IRA-International Journal of Education \& Multidisciplinary Studies

ISSN 2455-2526; Vol.03, Issue 03 (2016)

Institute of Research Advances

http://research-advances.org/index.php/IJEMS

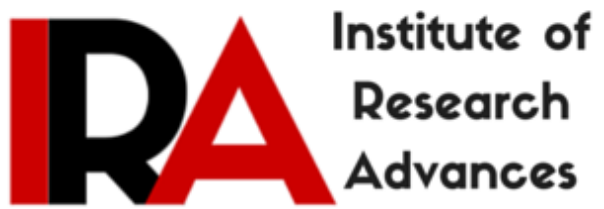

\title{
Proficiency Test of High School English Learners: A Case Study in Nayagarh Town
}

\author{
Dr. Govinda Chandra Penthoi \\ Guest Faculty, Dept. of Linguistics, \\ Berhampur University, \\ Bhanjabihar- 760007, India.
}

DOI: http://dx.doi.org/10.21013/jems.v3.n3.p21

\section{How to cite this paper:}

Penthoi, G. (2016). Proficiency Test of High School English Learners: A Case Study in Nayagarh Town. IRA International Journal of Education and Multidisciplinary Studies (ISSN 2455-2526), 3(3). doi:http://dx.doi.org/10.21013/jems.v3.n3.p21

(C) Institute of Research Advances

\section{(c)) EY-NC}

This works is licensed under a Creative Commons Attribution-Non Commercial 4.0 International License subject to proper citation to the publication source of the work.

Disclaimer: The scholarly papers as reviewed and published by the Institute of Research Advances (IRA) are the views and opinions of their respective authors and are not the views or opinions of the IRA. The IRA disclaims of any harm or loss caused due to the published content to any party. 


ABSTRACT
An attempt has been made to evaluate the learn ability of English as a second
language in two different kinds of instructions such as Oriya and English medium in
high school stage. Information has been collected from the both Oriya and English
medium schools. Some observations and generalizations made in order to arrive at
conclusions. The result of the present paper says that, the students with better socio-
economic back-grounds reveal better proficiency than that of the learners with low
socio-economic background. To add to it, learners with good socio-economic back-
ground get better exposure to the target language (i.e., English). However of learners
of English medium schools have better proficiency than that of learners of Oriya
medium schools.

\section{Introduction}

English in India has gained the status of second language, the language of communication, the official language and the link language in the multilingual situation. It is also the language of instructions in the higher education. Almost all entrance examinations to professional courses as well as to various jobs are held in English language, where not only the specific subjects are tested in English but also certain amount of proficiency in English language is tested.

Indian subcontinent is marked with the presence of four language families, they are Indo-Aryan Dravidian, Austro-Asiatic and Tibeto-Burman each further spreading into a vast number of languages. English since British imperialism has become the official link language in such a country with diversified linguistic situation. The impotence of English either be denied nor ignored in the international sphere

In the Indian context, English is learned in the classroom environmentthrough formal education. Although some elite children in urban societies learn to speak English at home not as a first language but as second language. Media like Television, Newspapers, internet and films also play an important role in assisting children to learn English factor these days. Psychological factors such as motivation, aptitude and sociological factors such as learners' socio-economic and parental background are also responsible for his learning English as a second language. Further, since English and the native languages belong to two different types of languages namely S.V.O. and S-O-V respectively it possesses certain problems for the Indian learner to learn English.

Similarly, while testing the proficiency in English in Indian context, one encounters with certain problems, such as how far the tests are valid and reliable. Are we making diagnostic test which will give us an idea of the kinds of grammatical points that will be tested or, are we making comprehension and vocabulary tests?

"The difficulties which are based on all evaluation procedures in education are twofold. The first is that we cannot treat teacher, pupil and materials as single variables. As we saw pupils vary among themselves in respect of a number of characteristics, some of which such as age and sex are easily measurable and therefore controllable, but others such as motivation, intelligence or aptitude present great difficulties in measurement. The methods the teacher employs are almost impossible to describe, standardize and controllable for experimental purposes. The second difficulty is just as serious since evaluation necessarily involves comparisons of this sort or another. It would be necessary to have the same children taught with same materials by two different teachers. But how can this are done? (Pit Corder, 1973). Another problem with testing proficiency is that one cannot test systematically 
any part of a language or type of performance in it, which we cannot describe in order to measure the learner's knowledge about the language one has to also measure his intelligence and knowledge about the world. In other words, the test must be valid.

As Palmer (1968) said "the validity of any examinations or test procedure may be broadly defined as the extent to which it does what it is intended to do".

The proficiency test in English also should be reliable. Pit Corder (1973) defines reliability in the following lines.

"Whether we are measuring learner's 'Communicative competence' or his 'grammatical competence', clearly we cannot examine his 'total knowledge', even if we know what this might mean. There simply would not be time. So we have to sample his knowledge, hoping that this sample is fair one, that it is the representative of his total knowledge we make therefore, a selection out of our description of the language of a set of items which we regard as a fair of representative one, and then test his knowledge of these. To do this we have of course, to have a model of some sort. The process of sampling depends on our 'construct' as we have called it in the discussion of validity'.

As suggested by Lado (1961) "the theory of language testing assumes the language is a system of habits of communication. Testing control of the problems is testing control of the language. Problems are those units and patterns that do not have counterpart in the native language or that have counterparts with structurally different distribution or meaning".

\section{Aim and objectives of the present study}

The present study deals with the proficiency test of English done at various high schools of Nayagarh, Orissa. For this purpose the students of Class X of both English medium as well as vernacular medium schools were tested. The aims and objectives of the study are to explore "the student's proficiency in learning the second language has any relationship with high and socio-economic background. In other words the test has been done with a view to see if socio-economic parameters are responsible for second language learning.

\section{Hypothesis}

We begin the study with a hypothesis that:

(i) Children with English medium schools are more proficient in English compression and Grammar.

(ii) Children who are exposed to English outside the classroom or from better socio-economic background are more proficient in English than their counterparts, who are less exposed or least privileged.

\section{Methodology}

We have used inductive method for doing this field work. Induction involves two-process observations and generalizations in this method we arrive at universal generalizations from particular facts. It is concerned with discovery in facts and relations between them. Observed fact (the tested data in this case) provide the base for this study.

Inductive method is scientific in character. Some the important theorems of physical and social sciences have been developed through this method. Observation and experiment jointly become the basis of induction. Experiment is controlled by 
observation. In the present study, samples used chosen from different schools in Nayagarh, Orissa, who were tested for proficiency in English language. The experiment was taken closely observed to arrive at some generalizations.

\section{Data collection and sampling}

Traditional theories deal with test of proficiency in native language / foreign language / second language. English in the Indian context occupies a peculiar position. Although English is an alien language, it is not as foreign to the Indian tongue as French or German. Due to the long establishment of English colony and introduction of the language in official language, the learner thinks of the overall meaning and proceeds to encode it in the linguistic forms of the foreign language. $\mathrm{He}$ transfers the habit system of his native language to the foreign tongue. When this transfer occurs, some of the units and patterns transferred will function satisfactorily in the foreign language and will not constitute a learning problem. Other units and patterns will into function satisfactorily in the foreign / second language. These constitute the real learning problems.

\section{Questionnaire}

As the total skills of speaking, listening, reading and writing could not be tested during such a short span of time, the present field study dealt with reading and writing skills only. Although this test will not cover the entire knowledge of the sample, it will certainly carryout a fairly good test of his proficiency in the language. We began our study by preparing questionnaire. This constitutes three sections.

(i) Grammar test

(ii) Comprehension test

(iii) Precise writing test.

Each questionnaire has to parts. Part-I caries the personal bio-data and Part-II subject test. Although some of the questions were subjective while others were subjective. Objectives tests are those that are scored rather mechanically without need to evaluating the complex performance on a scale. Subjective tests are those that require an opinion, a judgment on the part of the examiner. Objective test can test in a short time the major grammatical pattern or a representative sample of the vocabulary taught during a whole year or several years.

\section{Grammar test}

The term 'Grammar' means different things to different people. Modern grammarians since Otto Jespersen's time for English tried to collect and analyse examples of actual usage. Some linguistics such as C.C. Fries and other have recently attempted to lay bare the basic grammatical structure of English. From the modern linguistics point of view as proposed by Chomsky (1965) native speaker of a language has mastered the basic structure of his language, it is the basic underlying patterns on which he build sentences and sequences of sentences. So when the native speaker studies grammars he becomes involved not in the basic framework which he knows but in problems of variant usage of dialect differences of social differences of style, of artistic effects etc. In contrast with this, the non-native speaker who is learning the language does not know its structure. He needs to acquire this basic framework in order to master of the language.

Grammar testing poses certain problems. Are we testing what the student knows about the rules system or are we testing what he produce? Experience shows that a student who learns to use a certain structure under favourable classroom conditions may completely forget the same structure when facing a formal audience. 
The only way one can be sure of what a student does say is to observe him in all his sensitivities, since we could not afford to do this due to the constraint of time, we had to formulate the questionnaire very carefully. For doing this, we had to study what the students have already known. In other words, we had to know the level of proficiency the students are required to master in the previous class. Accordingly, the questions were formulated to see if the expectations are in resonance with the achievement. The same sets of questions were prepared for both Oriya and English medium school children, the children from different socio-economic background as all the children at +2 level have to go through the same sets of books. Hence, the level of proficiency required for all the children of Class $\mathrm{X}$ is the same.

\section{Reading comprehension test}

Reading in a second language consists of grasping meaning in that language through its written representation. In addition, sinc there are various purposes in reading. Reading for literary appreciation, for specific items of information, for significant information, in a given field, for example of usage etc. we further define reading in a second language as the grasping of the full linguistic meaning of the subject, which he reads Linguistics meanings are meant to include the denotations conveyed by the language. Properly included in linguistics meaning are the uses of lexical items in meanings that are normally brought out by the context even if such meanings would not be denied in the dictionaries of the language.

The technique used to test the reading comprehension consists of presenting to the students passages containing reading problems and testing his comprehension of the passage precisely at those points at which the problems are crucial.

\section{Precise writing tests}

Precise writing not only tests the comprehension of the given passage but also tests the ability to write the summary of the passage in one third words. It also in a way tests the student's commands over the vocabulary. In short, it tests the overall grasping of the language as well as the writing skill of the student.

\section{Data collection}

Once the questionnaire was formulated carefully, keeping the personal data as well as the linguistic data to test grammar, reading comprehension and précis writing, the field study was done in three schools of Nayagarh. These schools are M.V.M Schools (English medium) Brajendra High School (Oriya medium) and N.A.C High School (Oriya medium). The students were given to fill up the personal bio-data and answer the language questions within two hours. These data were further elicited, evaluated and tabulated to arrive at certain generalizations.

\section{Sampling}

The sampling was done at random which consists of students of both sexes, different socio-economic background, so that the samples represent the total picture.

\section{Data elicitation and scoring}

To measure is to compare a quantity that we cannot fully estimate with another quantity that is known and familiar. We can say that the quantity we are measuring is more than, less than, twice or whatever times larger than the known quantity with which we are comparing measuring it. The known quantity with which we compare those we wish to measure is the unit. The quantity being measured and the unit which we measure it must be comparable. In addition to knowing the number 
of units that the quantity contains we usually want to know whether this is enough for what we need or too much or not enough

Rank scores are based on ranking the students as high or low, top, middle or bottom, first, second, third, from the top, in comparison with other students.

Percentile scores are a much more refined and useful type of rank scores. Essentially a percentile score indicates the present of student that scored below it. A percentile scores of 60 means that 60 per cent students who took the test during the preparation of the norms made scores below one. A percentile score of 50 means that 50 percent of one half of the students made scores below it etc. This percentile score is not directly dependent on the number of times passed by the students but on the number of students who passed less than this one.

Percentile scores has many shortcomings as this scores do not scatter evenly throughout the scale but tend to cluster or bunch up near a centre and to thin over rear the wings of the scale.

\section{Standard score}

To overcome these difficulties we adopted standard scores of the test. That is we adopted the percentage of marks system. The total time allotted to answer the questions was two hours. The test was done out of 100 marks. For the reading of comprehension, 5 subjective questions were asked. Each carrying four marks, for each grammatical mistake $1 / 2$ mark was deducted and for each wrong answer or unattempted answer, no mark was given. Five more objective types of questions is Yes/ No type was also tested for reading comprehension, each carrying four marks. Multiple choice questions carrying 10 marks were also given in this section.

For the Grammar test fill in the blanks to test the use of article a, an or the use given. This test had five questions of two marks each. Matching the works from column A and B to test the knowledge or word and its meaning was given. Five such words use given each carrying two marks. Five more words were also given to make sentences, carrying two marks for each correct sentence.

The precise writing carried twenty marks. It had two sections (a) to write the summary of the paragraph in not more than twenty words and (b) to give the name of the paragraph each carrying ten marks.

\section{Scoring}

Once the test was conducted the marks were given to each answer keeping carefully in mind to test the spelling as well as the writing skills in mind. Then the marks / were tabulated in a separate sheets separately for comprehension test grammar test and précis writing test. Then the grand total of the marks secured use tabulated. The score sheets are attached herewith.

\section{Results and Discussion}

Earlier in this paper, we have said the proficiency test in English needs to be valid. Validity is essentially a matter of relevance is the test relevant to what it claims to measure. Since language is a highly structured and highly complex activity, a test needs to measure the language element or skill it purports to measure. We need to check the validity of the content of the items. If we use a questionnaire as the language is a highly complex activity, a test needs to measure the language element or skill it purports to measure. We need to check the validity of the content of the items. If we use a questionnaire as a language test, we will have to prove that the 
content of the interview either ranges over the entire system of the language or adequately samples it.

Modern linguistic analysis of the learning problems in a second language permits a highly refined study of the context of a language test. With the use of linguistic analysis and comparison of language we have located and described the significant elements that are most troublesome to a particular group of students. We are thus able to discuss content validity on more solid ground.

\section{Validity co-efficient}

The usual method of reporting the validity of a test is to give the correlation between its scores and those of the criterion. In case of the relation between scores on an English language proficiency test and the medium of instructions in school, the biserial co-efficient of correlation would be used because there are only two scores possible in the criterion; high or low.

In the present case, if the Oriya medium is given 1 and English medium is 2, the percentage of achievement (mean score) can be represented in the following figure-1

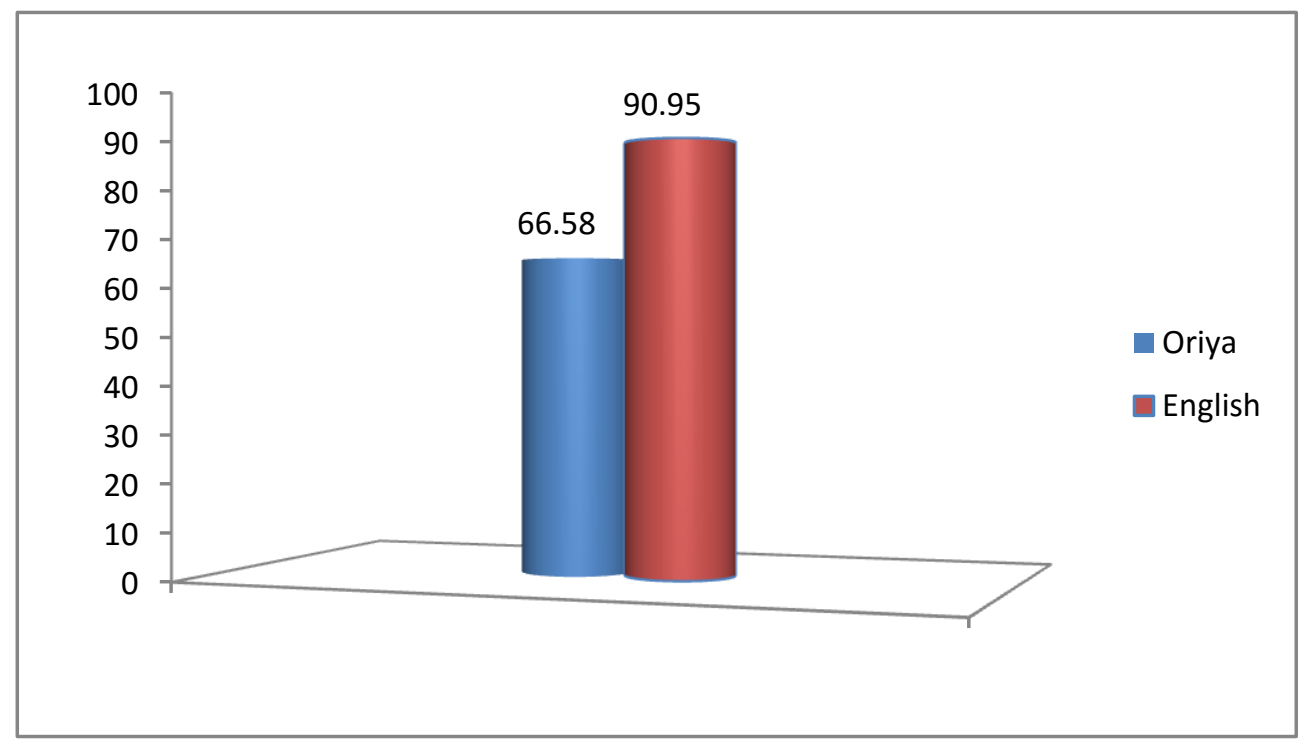

Fig. 1: Scores of percentage proficiency test in relation to medium of instruction.

It was found that not all the students of Oriya medium school students showed in low score. Some of them although the number is very few, showed as high as $80 \%$ or above. Most of the Oriya medium students have performed badly in précis writing test, although they did quite well in the reading comprehension and grammar test. However, the overall comparison showed the students from the English medium schools performed better than the students from the Oriya medium schools in each of the test held. Oriya medium school children showed low performance in précis writing shows their less command over the languages in general and writing skill in particular.

It was also observed that those few of the Oriya medium students fared better are from higher socio-economic background. Similarly all the students from English medium school are from higher socio-economic background. In other words, student's proficiency in second language learning is directly proportional to his socio- 
economic background. That is, higher the socio-economic background betters the proficiency in second language learning.

Fig. 2 shows the graphical representation of this.

Fig.2:

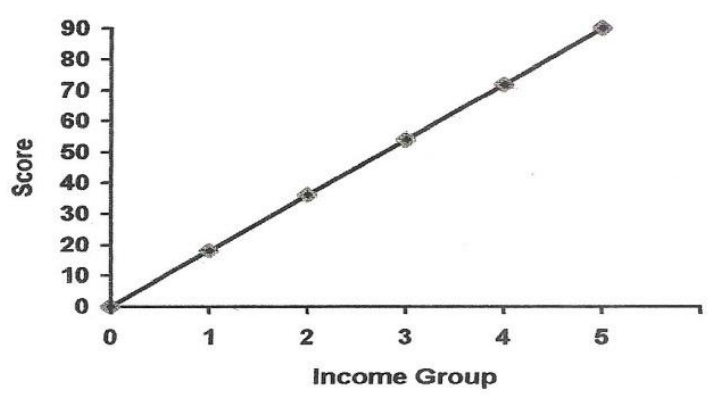

Relationship between socio economic background and percentage of scores 1-5 represent lower to higher income group.

\section{Reliability}

Reliability has to do with the stability of scores for the same individuals. If the scores of students are stable the test is reliable, If the scores tend to fluctuate for no apparent reason, the test is unreliable.

Validity is not possible unless the scores we deal with are stable, that is reliable validity refers to whether or not a test measures what is purports to measure. Reliability is a general quality of stability of scores regardless of what the test measures. Thus a test cannot be valid unless it is also reliable for an unreliable test does not measure.

The reliability of attest can be estimated by statistical means and is usually expressed in terms of the correlation of two sets of scores by the same students on the same test or equivalent forms of the same test. In the present study the scores of the two almost equivalent tests such as reading comprehension test and grammar test were co-related. A perfect reliability and would be expressed as 1.0. Such reliability would mean that each student made identical scores on both sets or that the differences if any were completely regular and exactly predicate. On the other hand, the absence of correlation would indicate complete unreliability of the test and would be expressed as 0.00 . These ratings have meaning in relation to each other, that is a higher co-efficient indicates higher reliability and for particular skills experience, shows that particular correlation co-efficient are good or poor depending on the skill and the use to be made of the test.

The present test shows a close relationship between the student's score in the reading comprehension test and that secured in the grammar test. Although the correlation does not show a perfect 1.00, in each of the student, it is quite close to it i.e., between 90 to 99 range. Lado (1961) says, "No language test shows a reliability of 1.00 or 0.00 the range between these two extremes". The reliability co-efficient of a given test is considered high or low not only according to how difficult to test that activity is and how stable the actual performance of the students in real life situation. Thus in general, written tests may be expected to show a higher co-efficient of 
reliability good vocabulary, structure and reading tests are usually in the 90 to 99 range."

\section{Conclusion}

The present paper "proficiency test of High School English Learners A case study in Nayagarh town" deals with the test carried out in various schools at Nayagarh for the class X students and the results of the test. The data was collected and quantified it was tested valid and reliable in order to make the tests and it runs more authentic.

Table-1

Total average score of the Oriya medium school

\begin{tabular}{|c|c|c|c|c|}
\hline School name & $\begin{array}{c}\text { Comprehension } \\
\text { test }\end{array}$ & $\begin{array}{c}\text { Grammar } \\
\text { test }\end{array}$ & Precise test & $\begin{array}{c}\text { Total marks } \\
\text { scored }\end{array}$ \\
\hline $1 . \quad \begin{array}{c}\text { B.H. School, } \\
\text { Nayagarh }\end{array}$ & $36.05 / 50$ & $23.9 / 30$ & $4.4 / 20$ & $64.35 / 100$ \\
\hline $\begin{array}{c}\text { N.A.C. High School, } \\
\text { Nayagarh }\end{array}$ & $35.95 / 50$ & $26.5 / 30$ & $6.2 / 20$ & $68.65 / 100$ \\
\hline $\begin{array}{l}\text { Total average score of } \\
\text { Oriya Medium school }\end{array}$ & $36 / 50$ & $25.2 / 30$ & $5.3 / 20$ & $66.5 / 100$ \\
\hline
\end{tabular}

Table-2

Total average score of the English medium school

\begin{tabular}{|cc|c|c|c|c|}
\hline School name & $\begin{array}{c}\text { Comprehension } \\
\text { test }\end{array}$ & $\begin{array}{c}\text { Grammar } \\
\text { test }\end{array}$ & Precise test & $\begin{array}{c}\text { Total marks } \\
\text { scored }\end{array}$ \\
\hline 3. & $\begin{array}{l}\text { M.V.M. English } \\
\text { Medium School }\end{array}$ & $46.3 / 50$ & $29.1 / 30$ & $15.55 / 20$ & $90.95 / 100$ \\
\hline
\end{tabular}

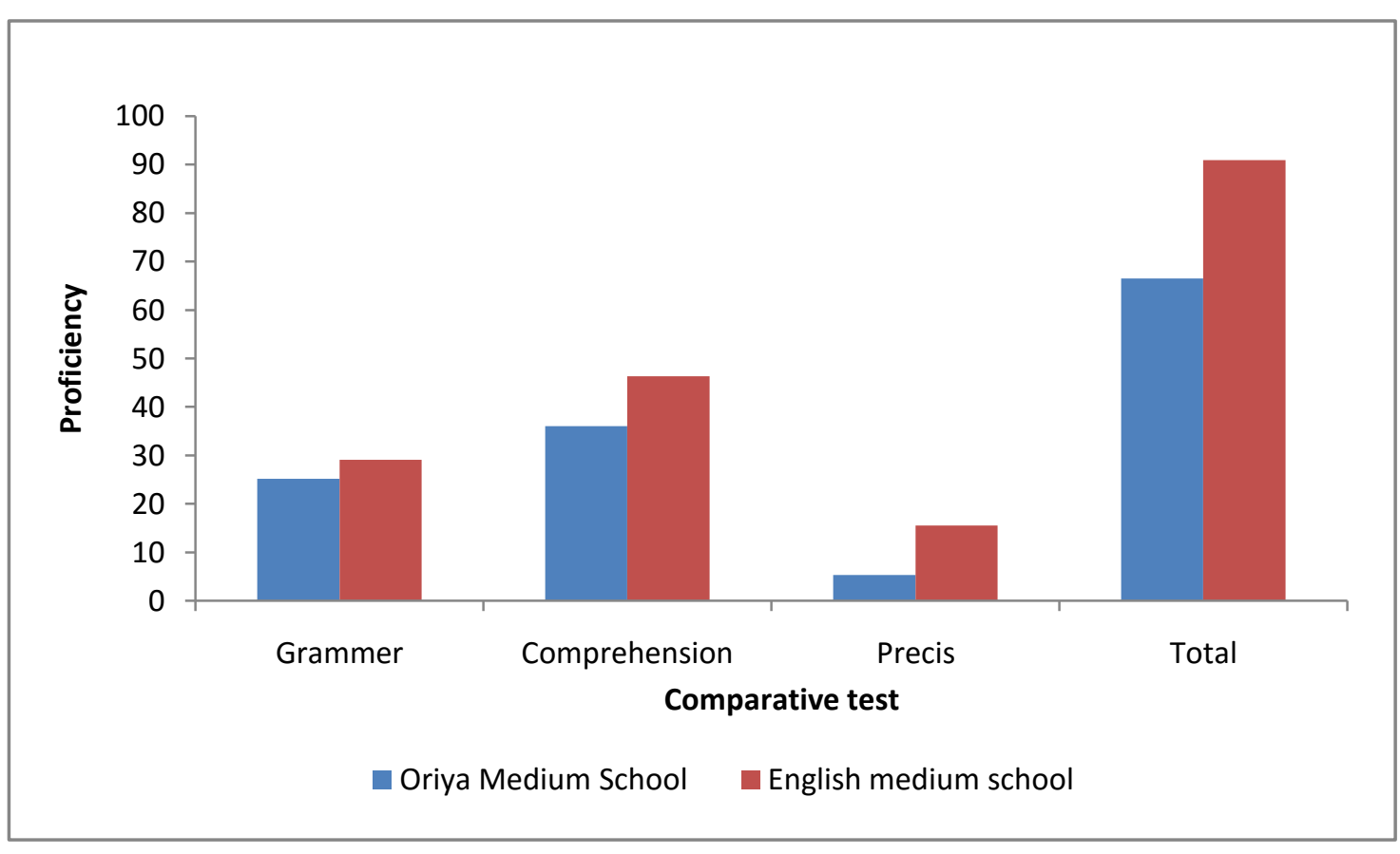




\section{Reference}

1. Abercrombie, M.L.J. 1970. Aims and Techniques in Group Teaching, London, Society for Research into Higher Education.

2. Alexander, L.G. 1971, Guided composition in English teaching, London, Longman.

3. Bialystok E. 1978, 'A theoretical method of second language learning'. Language Learning 28, 1 June: 69-84

4. Bright, J.A. and G.P. Mc Gregor 1970, Teaching English as a second language, London, Longman.

5. Brumfit, C.J. 1971, 'Second language teaching in the secondary school some principles," Bulletin of the Language Association of Tanzania, 3, 2 April 1826 (Cited from Brumfit 1980: 28-38)

6. Brumfit, C. Communicative methodology in language teaching. The rule of fluency and accuracy. Published by Cambridge University Press (1985).

7. Corder, S. Pit (1973. Language Teaching and Linguistic abstracts, 8, 4, October, 201-18.

8. Fredom, lain, S. 1976, 'Experimentation into foreign language teaching methodology: the research findings' system, 10, 2:119-33.

9. Gattengo, Caleb, 1972, teaching foreign language in School: The silent way, $2^{\text {nd }}$ Edn., New York, Educational solutions Inc. $11^{\text {th }}$ Edn. 1963

10. Mackey, W.F. 1965, Language Teaching Analysis, London, Longman.

11. Sajavaara, Kari, 1980. 'Psychollingustic models, Second language acquisition and contrastive analysis', mimeo, university of Jyrskyla.

12. Savignon, Sandra,J. 1972. Communicative competence: an experiment in foreign language teaching, Philadelphia, Centre for Curriculum Development.

13. Sutherland, Kenton, 1979, 'Accuracy vs. Fluency in the English language Classroom: Cross currents 6,2: 15-20

14. Wilkins, D.A., Linguistic in language teaching Great Britain, Edward Arnold, 1985. 